\title{
The Effect of the Feuerstein Project on the Cognitive and Functional State of Community-Dwelling Individuals Aged 65 Years and Older with Mild Cognitive Impairment: A Pilot Study
}

\author{
Uty Ostrei ${ }^{a, b} \quad$ Dikla Efrati-Chomsky ${ }^{a} \quad$ Ariela Zur ${ }^{c}$ Yael Robes-Alkalay ${ }^{d}$ \\ Ayala Nave $^{d} \quad$ Boris Punchik ${ }^{a, e, f} \quad$ Yan Press ${ }^{e, f}, g$ \\ ${ }^{a}$ Home Care Unit, Clalit Health Services, Beer Sheva, Israel; ${ }^{b}$ Soroka Medical Center, Clalit \\ Health Services, Beer Sheva, Israel; ${ }^{c}$ Clalit Health Services, Tel Aviv, Israel; ${ }^{d}$ Clalit Health \\ Services, Beer Sheva, Israel; ${ }^{e}$ Geriatric Unit, Division of Community Health, Ben-Gurion \\ University of the Negev, Beer Sheva, Israel; ${ }^{\text {DD }}$ epartment of Family Medicine, Sial Research \\ Center for Family Medicine and Primary Care, Faculty of Health Sciences, Ben-Gurion \\ University of the Negev, Beer Sheva, Israel; ${ }^{9}$ Department of Geriatrics, Soroka Medical \\ Center, Beer Sheva, Israel
}

\section{Keywords}

Mild cognitive impairment · Feuerstein Instrumental Enrichment (FIE) program · Cognitive training

\begin{abstract}
Background: The rate of elderly individuals with mild cognitive impairment $(\mathrm{MCl})$ has increased over recent decades. The Feuerstein Instrumental Enrichment (FIE) program for the elderly has been shown to be effective in various age groups but is has never been tested as a treatment for $\mathrm{MCl}$ in elderly patients. The aim of this study was to assess the effect of the FIE on the cognitive and functional state of elderly patients with $\mathrm{MCl}$. Methods: This was an interventional pilot study in community-dwelling patients aged $\geq 65$ years diagnosed with $\mathrm{MCl}$ in the previous year. The protocol included 30 twice-weekly 90 -min sessions with a full neurocognitive evaluation prior to the intervention ( $v 1)$, at its conclusion (v2), and half a year later (v3). Results: Nine of the 15 recruited participants completed the study. The mean age was 76.2 years. Compared to $\mathrm{v} 1$ and $\mathrm{v} 2$, the only significant improvements found at v3 were in the "visual perception" subtest of the NeuroTrax test and the total score of the MOCA test ( $p=$ 0.048 and 0.028 , respectively). The effect size was $>0.7(r=0.7)$, indicating a moderate-to-high clinical significance. The results of the qualitative questionnaire were consistent with the pos-
\end{abstract}


itive effect of the group on the fostering of social ties, the motivation to learn, the cognitive contribution, and the development of a sense of self-efficacy. Conclusion: The study findings support the conclusion that an intervention with a focus on cognitive exercising can promote a feeling of self-efficacy and preserve some cognitive skills.

\section{Introduction}

Over the last decades, there has been an increase in longevity [1], with corresponding increases in the number of individuals aged $\geq 65$ years in the population and the prevalence of mild cognitive impairment (MCI) $[2,3]$. MCI is a concept that describes any reported cognitive impairment, together with objective evidence of a cognitive decline, without any significant effect on daily function [4]. Elderly patients diagnosed with MCI have a 5-15\% annual risk of developing dementia, especially the Alzheimer type [5]. Thus, it is very important to find ways to prevent progression of MCI to dementia [6, 7].

Nonpharmacological interventions have been successful in slowing down the process of cognitive decline and the maintenance of daily function. The Finnish study [8] found that a multidimensional intervention which included cognitive training maintained or improved cognitive function. Motes et al. [9] found that cognitive training was associated with a significant improvement in the speed of data processing and the learning ability of the study participants. The Feuerstein Enrichment (FIE) program for the elderly $[10,11]$ is an intervention based on stimulation of specific areas in the cortex, with the aim of fostering neuronal plasticity, the development of awareness in the elderly of their learning and thinking processes (metacognition, the acquisition of control of thinking skills, the enhancement of self-efficacy [11], and the prevention of mental decline [10].

Despite the demonstrated advantages of the Feuerstein method in other age groups, it has not been tested in individuals $\geq 65$ years of age with MCI.

\section{Materials and Methods}

An interventional pilot study was conducted within the framework of the Comprehensive Geriatric Assessment Unit in the southern district of the Clalit Health Services in Beer-Sheva, Israel. We included the first 15 patients appearing on the database of the unit diagnosed with $\mathrm{MCI}$ in the year prior to the beginning of the study who met the inclusion criteria and agreed to participate in the study.

The study included men and women aged $\geq 65$ years who spoke and read Hebrew and who had been diagnosed in the previous year, by a specialist in geriatric medicine, as suffering from MCI based on the consensus criteria [4] and with a Memory Index score in the NeuroTrax test [12] of $<95$.

The study excluded patients with an unstable disease such as severe heart failure, unstable coronary artery disease, a pulmonary condition causing dyspnea at minimal effort, refractory pain, mobility difficulties outside of the home, those diagnosed with a cognitive problem other than MCI (delirium, dementia, or retardation), a visual impairment that could not be corrected with glasses, or a hearing impairment that could not be corrected with a hearing aid.

\section{Karger'}




\section{Study Protocol}

A geriatrician from the Geriatrics Clinic in Beer-Sheva identified patients who met the study criteria. An occupational therapist (OT) conducted a phone discussion with each candidate. Patients who expressed an interest in participating in the study were invited to an appointment in which they received information about the study and the inclusion and exclusion criteria were reviewed again. For the rest of the meeting, the patients underwent a cognitive and functional evaluation (prescreening) conducted by the OT using the instruments described below.

The primary outcome was a change in cognitive state as measured by the following tests:

1 The Montreal Cognitive Assessment (MoCA): a screening test that uses an instrument for the identification of MCI, validated in Hebrew $[13,14]$ with cut-off point for MCI of 26 of 30 points.

2 The NeuroTrax test (Mindstream): a computerized assessment test that uses an instrument for the identification of $\mathrm{MCI}[12,15]$, with a cut-off score of the Memory Index for MCI of $<95$.

3 Dysexecutive questionnaire (DEX): a self-administered questionnaire that deals with executive functions and evaluates 3 functional aspects: behavior, cognition, and emotions, with scores from "never" ( 0 points) to "very often" ( 4 points). The score range is from 0 to 80, with a high score representing problems with executive functions [16].

Secondary outcomes were changes in function and participation using the following instruments:

1 The Canadian Occupational Performance Measure (COPM) [17]: a semi-structured test, based on the Activity Card Sort (ACS) $[18,19]$ and a personal interview, which measures the individual's perceptions relating to self-treatment, creativity, and leisure. A separate score is given to the level of execution and related satisfaction. The percentage change in these 2 scores is assessed by repeating the test [17].

2 Activity Card Sort (ACS): a test that evaluates participation in leisure-time activities and spatial function in terms of the past and present [18]. The score reflects the present level of function in relation to function in the past [19].

3 Qualitative Questionnaire. A personal interview was conducted with each of the participants, including 4 open questions about different aspects of the course. The participant's responses were document in writing by the interviewer.

\section{Intervention and Follow-Up}

The patients who were recruited for the study participated in the FIE program. A teacher from the Feuerstein Center mediated the group and kept a close record of participation in the meetings. The program included 30 twice-weekly sessions that lasted for $90 \mathrm{~min}$ each, with repeat assessments at the end of the 30 sessions and half a year later, that included all the tests described above.

\section{Statistical Analyses}

Quantitative data analyses were conducted with SPSS software v22. A comparison was conducted for each of the cognitive tests and changes in function and participation (by means of MoCA, the NeuroTrax test, ACS, and DEX) were determined at 3 time points: preintervention (v1), at the end of the intervention (v2), and half a year after the intervention (v3). Comparisons were performed using the Wilcoxon signed-ranks test. The clinical size effect was calculated for test results with this test using the following formula: $r=\mathrm{z} / \operatorname{sqrt}\left(\mathrm{n}_{1}+\mathrm{n}_{2}\right)$ according to Cohen's criteria for effect size. Responses to the qualitative questionnaire were collected, and 6 investigators acting independently extracted central themes from the response.

\section{Karger'}


Dementia and Geriatric Cognitive Disorders Extra

Table 1. Sociodemographic characteristics of the study population $(n=9)$

\begin{tabular}{|c|c|}
\hline \multicolumn{2}{|c|}{ Dement Geriatr Cogn Disord Extra 2020;10:135-142 } \\
\hline DOI: 10.1159/000509892 & $\begin{array}{l}\text { (c) } 2020 \text { The Author(s). Published by S. Karger AG, Basel } \\
\text { www.karger.com/dee }\end{array}$ \\
\hline
\end{tabular}

\begin{tabular}{|c|c|}
\hline \multicolumn{2}{|l|}{ Sex } \\
\hline Male & $5(55.6)$ \\
\hline Female & $4(44.4)$ \\
\hline \multicolumn{2}{|l|}{ Age } \\
\hline $65-60$ years & $1(11.1)$ \\
\hline 71-75 years & $3(33.3)$ \\
\hline $76-80$ years & $2(22.2)$ \\
\hline$\geq 81$ years & $3(33.3)$ \\
\hline Mean \pm SD, years & $76.2 \pm 4.9$ \\
\hline Range, years & $67-81$ \\
\hline Median, years & 77 \\
\hline \multicolumn{2}{|l|}{ Family status } \\
\hline Married & $5(55.6)$ \\
\hline Divorced & $2(22.2)$ \\
\hline Widow/widower & $2(22.2)$ \\
\hline \multicolumn{2}{|l|}{ Education } \\
\hline Elementary & $3(33.3)$ \\
\hline High school & $4(44.4)$ \\
\hline Academic & $2(22.2)$ \\
\hline \multicolumn{2}{|l|}{ Years in education } \\
\hline Mean \pm SD & $11.0 \pm 3.5$ \\
\hline Range & $4-16$ \\
\hline Median & 12 \\
\hline \multicolumn{2}{|l|}{ Work status } \\
\hline Retired & $9(100)$ \\
\hline \multicolumn{2}{|l|}{ Residence } \\
\hline Urban & $7(77.8)$ \\
\hline Small community & $1(11.1)$ \\
\hline Retirement home & $1(11.1)$ \\
\hline \multicolumn{2}{|c|}{ Religiosity (self-definition) } \\
\hline Secular & $4(44.4)$ \\
\hline Traditional & $3(33.3)$ \\
\hline Religious & $2(22.2)$ \\
\hline
\end{tabular}

Values express $n(\%)$, unless otherwise indicated.

\section{Results}

Four of the 15 patients who met the inclusion criteria and signed the informed consent had a Memory Index score of $>95$ in the NeuroTrax test, so they did not move on to the intervention phase. Two of the 11 who began the intervention stopped participating after the first session.

Table 1 shows the characteristics of the 9 participants who attended the intervention sessions. Their mean age was $76.2 \pm 4.9$ years and $44.4 \%$ were women. The participation rate was $92 \%$.

Table 2 shows the results of the tests at v1, v2, and v3. The comparison between v1 and v2 found a significant improvement at the end of the intervention only in the "visuospatial perception" subtest of the NeuroTrax test and in the overall score of the MoCA test ( $p=0.028$ and $p=0.048$, respectively). In both cases, the size effect was $>0.7(r>0.7)$, indicative of a moderate-to-high clinical significance.

When v1 and v3 were compared, the only improvement that was maintained was in the "visuospatial perception" subtest of NeuroTrax $(p=0.018)$. The size effect, $r=0.79$, was indicative of a moderate-to-high clinical significance. 
Table 2. Comparison of test results prior to the intervention (v1), at its conclusion (v2), and half a year later (v3)

\begin{tabular}{|c|c|c|c|c|c|c|c|c|c|c|c|c|c|}
\hline & \multicolumn{3}{|c|}{ v1 percentiles } & \multicolumn{3}{|c|}{ v2 percentiles } & \multicolumn{3}{|c|}{ v3 percentiles } & \multirow{2}{*}{$\begin{array}{l}p \\
\mathrm{v} 1: \mathrm{v} 2\end{array}$} & \multirow{2}{*}{$\begin{array}{l}\text { Effect } \\
\text { size }\end{array}$} & \multirow{2}{*}{$\begin{array}{l}p \\
\mathrm{v} 1: \mathrm{v} 3\end{array}$} & \multirow{2}{*}{$\begin{array}{l}\text { Effect } \\
\text { size }\end{array}$} \\
\hline & 25 th & 50 th & 75 th & 25 th & 50th & 75 th & 25 th & 50 th & 75th & & & & \\
\hline \multicolumn{14}{|l|}{ NeuroTrax } \\
\hline Global score & 85.4 & 89.1 & 92.0 & 80.2 & 90.0 & 100.1 & 82.5 & 86.2 & 96.1 & 0.484 & -0.247 & 0.813 & -0.07 \\
\hline Memory & 75.9 & 79.9 & 82.4 & 72.3 & 80.5 & 92.5 & 75.9 & 82.9 & 88.5 & 0.499 & -0.239 & 0.343 & -0.32 \\
\hline Executive function & 82.5 & 92.6 & 99.9 & 85.8 & 92.4 & 96.5 & 79.4 & 91.7 & 96.8 & 0.889 & -0.049 & 0.260 & -0.38 \\
\hline Attention & 93.6 & 99.1 & 104.1 & 90.7 & 96.8 & 101.9 & 81.3 & 92.7 & 100.7 & 0.674 & -0.148 & 0.110 & -0.53 \\
\hline Visuospatial perception & 77.5 & 82.6 & 90.6 & 78.8 & 89.0 & 105.6 & 83.7 & 97.1 & 101.8 & 0.028 & -0.776 & 0.018 & -0.79 \\
\hline \multicolumn{14}{|l|}{ MoCA } \\
\hline Global score & 18 & 20 & 22 & 19.2 & 22 & 23 & 18 & 21 & 24.5 & 0.048 & -0.7 & 0.244 & -0.39 \\
\hline \multicolumn{14}{|l|}{ Activity card sort } \\
\hline IADL & 0.8 & 0.9 & 0.94 & 0.79 & 0.91 & 0.9 & 0.8 & 0.9 & 0.9 & 0.609 & -0.181 & 0.672 & -0.14 \\
\hline Leisure - social cultural & 0.6 & 0.7 & 0.8 & 0.6 & 0.7 & 0.9 & 0.6 & 0.9 & 0.9 & 0.889 & -0.049 & 0.374 & -0.3 \\
\hline Leisure - low physical & 0.6 & 0.8 & 0.9 & 0.6 & 0.8 & 0.9 & 0.8 & 0.9 & 0.9 & 1.000 & 0 & 0.138 & -0.49 \\
\hline Leisure - high physical & 0.5 & 0.5 & 0.6 & 0.4 & 0.5 & 0.8 & 0.3 & 0.8 & 0.9 & 0.176 & -0.478 & 0.407 & -0.28 \\
\hline Final score & 0.7 & 0.8 & 0.8 & 0.7 & 0.8 & 0.9 & 0.6 & 0.9 & 0.9 & 0.624 & -0.173 & 0.674 & -0.14 \\
\hline \multicolumn{14}{|c|}{ Dysexecutive questionnaire } \\
\hline DEX total & 11.5 & 27 & 34 & 15 & 17 & 26.5 & 13.5 & 19 & 30 & 0.446 & -0.269 & 0.213 & -0.42 \\
\hline
\end{tabular}

Five central themes were identified at the initial interviews using the qualitative questionnaire. They were associated with the following patient experiences: (a) cognitive contribution, (b) social ties, (c) interest and significance, (d) satisfaction with the teacher, and (e) learning and challenge.

Six participants reported a cognitive contribution, in that they felt there was an improvement in their thinking processes. One of the participants said: "I play bridge and this helped me to lose less, I improved..." Another patient said: "I think it had a positive effect on my memory."

Six participants reported social ties that developed as a result of the meetings. One participant said: "...We were like a family, everyone was concerned about and helped each other. It was like we knew each other for years..." A second participant reported on a strong friendship that developed during the program and helped her to deal with loneliness: "It was difficult for me to be alone. Now it is much less so. Now I have this friend. We don't leave each other, she comes to me and that's important to me."

In terms of interest and significance, 3 participants reported a new significance in their lives following the program. One reported that "the group gave me new life."

Six participants reported that they were satisfied with the teacher: "an excellent teacher," "the teacher was good and pleasant and experienced."

Three participants reported that the course motivated them to learn. One said: "If I didn't succeed in doing something on a particular day, I stayed awake until 2 a.m. to continue." A second participant said that the course motivated him to preserve his abilities: "I make an effort to maintain appropriate thinking."

\section{Discussion}

The aim of this study was to assess the effect of the FIE program on the cognitive and functional state of patients $\geq 65$ years with a diagnosis of MCI. It was a pilot study, so the sample size was not planned to detect statistically significant differences. However, at the end of the intervention, there was a significant improvement in "visuospatial perception" in the 
NeuroTraxtest as well as in the MoCA test, with the improvement in the visuospatial perception test being maintained at $\mathrm{v}$.

These results are consistent with the perspective presented in the paper of Feuerstein et al. [11], in that interventions focused on the function of specific cortical regions improve function. These results are also supported by other studies that have shown that cognitive training can improve the areas that are exercised [20]. Feuerstein et al. [11] anticipated there would be an improvement in performing the instrumental activities of daily living (IADL) by raising participants' awareness of their abilities, even though, in reality, the function level was not assessed and no significant change was found in daily function. However, the results of Rebok and Ball [20] showed that a cognitive intervention that focused on memory, logical deduction, and the speed of data processing, preserved IADL in the long term. Such results should drive ongoing research into the association between focused cognitive interventions and improved IADL function.

In this study, no statistically significant differences were noted in the DEX, COPM, and ACS tests. There are several possible explanations for these results: the small sample size, i.e., not large enough to detect differences, the focus of the FIE program on specific cognitive skills and not executive functions, and the predetermined ceiling effect for these tests in this specific population due to the definition of $\mathrm{MCI}$, i.e., a state of cognitive impairment that does not lead to an essential loss of daily function.

The results in the qualitative part of the study were more significant. The central themes that were identified provided evidence of the group's contribution to the fostering of social ties, a new significance to life, the motivation to learn, and a cognitive contribution. These themes show the influence of the group framework and are not necessarily dependent on the program's cognitive training. The social participation, and the intensity of the sessions and their duration promoted social cohesiveness. These effects are important and significant. They reflect the process that the participants underwent in developing a sense of self-efficacy and the effect that this had on their quality of life. The patients' feelings were consistent with the principles that underlie the FIE program, which emphasizes experiencing success in the execution and awareness of this experience to improve feelings of self-efficacy [11].

The strengths of the study were: it is the first pilot study to investigate the effect of the FIE program in patients with MCI, the long follow-up period, and the use of multiple instruments for cognitive and functional assessment. Limitations were the small sample size and the absence of a control group.

\section{Conclusion}

There was a positive association between an activity that focused on cognitive content and the maintenance of cognitive function. The empirical and qualitative results of the study, taken together, support the basic concept of the FIE program, i.e., that interventions focused on cognitive training enhance the sense of efficacy, preserve cognitive skills, and improve perceptual function. However, to validate this, a study will have to be conducted with a control group and a larger sample size.

The study demonstrated a significant improvement in perceptual function that was maintained over time. This is consistent with the findings of other studies that proved that an intervention that focuses on a specific cognitive function can improve this function [9]. There is therefore a rationale to continue to study the association between social participation and cognitive training, by focusing on occupation and daily function. 


\section{Statement of Ethics}

The study was approved by the Ethics Committee for Studies in the Community at the Meir Medical Center in Kfar Saba (approval No. 0206-16-COM1). All the participants signed informed consent forms.

\section{Conflict of Interest Statement}

The authors declare no conflicts of interest.

\section{Funding Sources}

There was no funding.

\section{Author Contributions}

U.O. and D.E.-C.: acquisition of subjects and/or data, analysis and interpretation of data, and preparation of the manuscript. A.Z.: study concept and design and acquisition of subjects and/or data. Y.R.-A. and B.P.: analysis and interpretation of data and preparation of the manuscript. A.N.: acquisition of subjects and/or data and analysis and interpretation of data. Y.P.: study concept and design, acquisition of subjects and/or data, analysis and interpretation of data, and preparation of the manuscript.

\section{References}

1 The 65+ Population in Israel: Statistical Abstract 2016 Myers-JDC-Brookdale Institute. Israel; 2016.

2 Ritchie K. Mild cognitive impairment: an epidemiological perspective. Dialogues Clin Neurosci. 2004 Dec;6(4): 401-8.

3 Luck T, Luppa M, Briel S, Riedel-Heller SG. Incidence of mild cognitive impairment: a systematic review. Dement Geriatr Cogn Disord. 2010;29(2):164-75.

4 Petersen RC, Caracciolo B, Brayne C, Gauthier S, Jelic V, Fratiglioni L. Mild cognitive impairment: a concept in evolution. J Intern Med. 2014 Mar;275(3):214-28.

5 Shim SM, Song J, Kim JH, Jeon JP. Conversion pattern and predictive factor of mild cognitive impairment in elderly Koreans. Arch Gerontol Geriatr. 2016 May-Jun;64:146-50.

6 Kane RL, Butler M, Fink HA, Brasure M, Davila H, Desai P, et al. Interventions to Prevent Age-Related Cognitive Decline. Mild Cognitive Impairment, and Clinical Alzheimer's-Type Dementia [Internet]. Rockville (MD): Agency for Healthcare Research and Quality (US); 2017.

7 Vega JN, Newhouse PA. Mild cognitive impairment: diagnosis, longitudinal course, and emerging treatments. Curr Psychiatry Rep. 2014 Oct; 16(10):490.

8 Ngandu T, Lehtisalo J, Solomon A, Levälahti E, Ahtiluoto S, Antikainen R, et al. A 2 year multidomain intervention of diet, exercise, cognitive training, and vascular risk monitoring versus control to prevent cognitive decline in at-risk elderly people (FINGER): a randomised controlled trial. Lancet. 2015 Jun;385(9984):225563.

9 Motes MA, Yezhuvath US, Aslan S, Spence JS, Rypma B, Chapman SB. Higher-order cognitive training effects on processing speed-related neural activity: a randomized trial. Neurobiol Aging. 2018 Feb;62:72-81.

10 Feuerstein R. Instrumental enrichment: an intervention program for cognitive modifiability. 1980.

11 Feuerstein R, Falik LH, Feuerstein RS, Cagan A, Yosef L, Rosen S, et al. Cognitive enhancement and rehabilitation for the elder population: Application of the Feuerstein Instrumental Enrichment Program for the Elderly. Life Span and Disability. 2012;15(2):21-33.

12 Dwolatzky T, Whitehead V, Doniger GM, Simon ES, Schweiger A, Jaffe D, et al. Validity of a novel computerized cognitive battery for mild cognitive impairment. BMC Geriatr. 2003 Nov;3(1):4. 
13 Lifshitz M, Dwolatzky T, Press Y. Validation of the Hebrew version of the MoCA test as a screening instrument for the early detection of mild cognitive impairment in elderly individuals. J Geriatr Psychiatry Neurol. 2012 Sep;25(3):155-61.

14 Nasreddine ZS, Phillips NA, Bédirian V, Charbonneau S, Whitehead V, Collin I, et al. The Montreal Cognitive Assessment, MoCA: a brief screening tool for mild cognitive impairment. J Am Geriatr Soc. 2005 Apr;53(4): 695-9.

15 Schweiger A, Doniger GM, Dwolatzky T, Jaffe D, Simon ES. Reliability of a novel computerized neuropsychological battery for mild cognitive impairment. Acta Neuropsychol. 2003;1(4):407-13.

16 Wilson BA, Evans JJ, Emslie H, Alderman N, Burgess P. The Development of an Ecologically Valid Test for Assessing Patients with a Dysexecutive Syndrome. Neuropsychol Rehabil. 1998;8(3):213-28.

17 Law M, Baptiste S, McColl M, Opzoomer A, Polatajko H, Pollock N. The Canadian occupational performance measure: an outcome measure for occupational therapy. Can J Occup Ther. 1990 Apr;57(2):82-7.

18 Baum C, Edwards D. Activity Card Sort Test Kit. 2001.

19 Katz N, Karpin H, Lak A, Furman T, Hartman-Maeir A. Participation in occupational performance: reliability and validity of the activity card sort. OTJR (Thorofare, NJ). 2003;23(1):10-7.

20 Rebok GW, Ball K, Guey LT, Jones RN, Kim H-Y, King JW, et al. Ten-Year Effects of the ACTIVE Cognitive Training Trial on Cognition and Everyday Functioning in Older Adults. J Am Geriatr Soc. 2014;62(1):16-24. 